\title{
Chinese Students' Goal Orientation in English Learning: A Study Based on Autonomous Inquiry Model
}

\author{
Jianfeng Zhang ${ }^{1}$ \\ ${ }^{1}$ College of Humanities and Foreign Languages, Xi' an University of Science and Technology, China \\ Correspondence: Jianfeng Zhang, College of Humanities and Foreign Languages, Xi'an University of \\ Science and Technology, Lintong District, 710600, Xi'an city, Shaanxi Province, China. Tel: \\ 86-180-669-771-27. E-mail: zhangjianfeng091024@126.com
}

Received: November 27, 2013 Accepted: December 22, 2013 Online Published: January 6, 2014

doi:10.5539/elt.v7n2p84 URL: http://dx.doi.org/10.5539/elt.v7n2p84

The research is financed by Scientific Research Program Funded by Shaanxi Provincial Education Department (Program No. 12JK0297).

\begin{abstract}
Goal orientation is a kind of theory of learning motivation, which helps learners to develop their capability by emphasis on new techniques acquiring and environment adapting. In this study, based on the autonomous inquiry model, the construction of Chinese students' goal orientations in English learning are summarized according to the data analysis. Besides, the relationship between learning goal orientations and language instruction is explored in the English as Foreign Language environment. The results indicate that in the autonomous inquiry model, the performance of English language teaching can be improved significantly; moreover, in China, most learners have performance goals; in contrast with mastery goals, performance goals enhance the teaching performance definitely.
\end{abstract}

Keywords: learning goal orientation, autonomous inquiry, teaching performance

\section{Introduction}

Autonomous inquiry learning is the synthetic practice, which mainly depends on learners to experience, renovate and create knowledge and to solve the problems with the acquired knowledge by themselves. Through active inquiry, learners can activate and maintain the learning motivations so that the output can be acquired. Meanwhile, in the studies of learning motivations in SLA (Second Language Acquisition), goal orientation is usually viewed as one of important factors. Gardner (Gardner, 1993) indicates that learning motivations are based on learning goal orientations and different goal orientations lead to the differences of motivation. Numerous researches show that goal orientations not only are able to stimulate learning motivations and to arouse learners' interest but also play vital roles in adopting learning strategies and adjusting to emotions as well as feelings (Pintrich, 2000).

The research findings of goal orientations, however, usually rely on psychological levels, which focus on its classifications and relationship among various variables. It is rare to combine the autonomous inquiry learning model and goal orientations in English learning with empirical study from the perspective of SLA. Therefore, in this paper, based on the autonomous inquiry model, it analyzes and summarizes the constructions of Chinese students' goal orientations in English learning via tests and questionnaires. On the other hand, the relationship between learning goal orientations and teaching performance is explored to renovate a learning model in the English as Foreign Language environment.

\section{Literature Review}

\subsection{The Autonomous Inquiry Learning}

The autonomous inquiry is mainly based on cognitive psychology, humanistic psychology and constructivism (Zhang, 2013). American educational psychologist Bruner (Bruner, 1967) puts forward cognitive structural theory of learning that is also called discovery learning theory. He indicates that if learners try to perform well, it is necessary to provide specific information, but grasping information is not 
the essential purpose of learning, which should be a particular cognitive procedure to help or form wisdom as well as cognition. Compared with former scholars, Bruner pays more attention to the theoretical basis of learning models that are based on scientific researches.

In addition, another important basis of autonomous inquiry learning is humanistic psychology which mainly stresses on the functions, purposes and goals of education. Educators of humanism hold that education should focus on enough self actualization, which is characterized by strong creativity (Metallidou, 2010). Therefore, learners will develop their potential and make great progress, if their initiative or uniqueness is respected and they are given individual self realization.

Besides, learning theory of constructivism emphasize that knowledge is the subjective intrinsic performance of objective reality. Moreover, knowledge is constructed through the interactivity between individual and physical environment as well as social interaction (Kumar, 2011). Ideal learning should include four parts: context, collaboration, communication and meaning construction. So, based on constructivism, autonomous inquiry learning indicates that learners lie in the centre of the whole process of learning and they belong to active constructors of meaning, not the passive acceptors.

According to the National Science Education Standards of America, autonomous inquiry learning is defined as "students must involve in inquiry-oriented investigations in which they interact with their teachers and peers. Students establish connections between their current knowledge of science and the scientific knowledge found in many sources; they apply science content to new questions; they engage in problem solving, planning, decision making, and group discussions; and they experience assessments that are consistent with an active approach to learning." (National research Council, 1996)

Generally speaking, autonomous inquiry can be viewed as a systematic learning model, which emphasizes that learners inquire knowledge actively (Qian, 2002). As the dominators of learning, learners should accomplish inquiring tasks, grasp the relevant theories and then solve problems by careful observation, reading, considering, testing, listening and discussion.

\subsection{Learning Goal Orientation}

The concept of goal orientation is first proposed by Dweck and his colleagues who studied the performance of the primary school children (Kadivar, 2011). Goal orientation signifies the coherent pattern of motivation which causes individuals to improve their capacities through learning new skills as well as through adapting new environment and finally to show a response.

Ames indicates that goal orientation is one's consciousness of work, learning, performance and achievement, which can be viewed as an integrant of self efficacy, attribution and emotion (Ames, 1992). Self efficacy addresses the capacity for self evaluation; attribution shows the interpretation of reasons for success or failure; emotion displays the reaction to behaviour and work outcomes.

Besides, Pintrich defines goal orientation as individual's reasons of seeking successful tasks, which reflect the intrinsic cognitive orientations. Therefore, goal orientation is an organized standard system that includes aims, competence, success, ability, efforts and criteria (Pintrich, 1995).

Learning goal orientation belongs to an important variable in learning motivation. As learners participate the specific learning task, learning goal orientation provides objectives and directs the orientations of achievement that learners pursue in their own bosom (Bartels, 2009). At present, most scholars agree that learning goal orientation can be divided into mastery goals and performance goals (Bjørnebekk, 2010). Mastery goal orientation focuses on mastering knowledge, enhancing ability, so objectives and learning tasks are put the first place; performance goal orientation, however, learners utilize other-referenced standards, which minimize errors at the cost of fulfilling tasks, to define their competence, are concerned about their capacity and achievement outperformed than others (Michou, 2013).

\subsection{Goal Orientation in English Learning Based on Autonomous Inquiry Model}

Autonomous inquiry model is a complete cyclic process, which organically links the leading role of instructors, the main role of learners, the exemplary role of textbooks and the interaction among students. Tasks are deliberately designed by instructors and contents of English language teaching are subtly hidden in tasks; then, inquiry tasks that are moderate and logical are proposed to attract learners' attention, to arouse their curiosity so that they are interested in what they will learn and gradually stimulate their motivation; next, learners are expected to made some hypotheses through reading, demonstrating, observing and thinking. In the process of inquiry, learners are not only in active exploration, thinking, constructing meaning, but also they absorb, internalize and enhance language skills; finally, the results of the inquiry are 
collected and the quality of learning activities will be assessed timely, comprehensively, objectively, scientifically and accurately to guarantee the authenticity of outcomes.

On this basis, the construction of Chinese students' goal orientations in English learning during the whole inquiry process from the motivation stimulation to outcomes evaluation should be explored; what's more, the relationship between learning goal orientations and language instruction need be analyzed in the English as Foreign Language environment. Therefore, it is necessary and significant to research in this area.

\section{Research Methodology}

\subsection{Subjects}

The 125 subjects who are freshmen are chosen from Xi'an University of Science and Technology. The details are shown in Table 1.

Table 1. Basic information of subjects

\begin{tabular}{lllll}
\hline & $\mathrm{N}$ & Male & Female & Average age \\
\hline Class 1 & 62 & 42 & 20 & 19.8 \\
Class 2 & 63 & 50 & 13 & 19.4 \\
\hline Total & 125 & 92 & 33 & 19.6 \\
\hline
\end{tabular}

These subjects are randomly divided into two classes, which having identical English teacher, learning materials, learning environment and the same class time ( 6 classes per week). Because the construction and the relationship between goal orientations and learning performance will be explored in this research, the impact of variables, such as gender and age, is not considered. In addition, as freshmen, subjects have just entered campus, so they should be interested in novel learning model; and they temporarily don't have the burden for CET4 (College English Test 4), so their learning should be less utilitarianism; as adults, they have already learned English for more than 6 years, which can ensure that they are provided with sufficient ability and knowledge to autonomous inquiry, so the reliability of the study will be guaranteed.

\subsection{Procedures}

The study is divided into 2 stages and lasts 33 weeks (the first stage lasts 16 weeks and the second stage lasts 17 weeks). During the whole process, students use autonomous inquiry model to learn English. At first, a pre-test is arranged to test the similarity of achievements. After the first stage, a mid-test is hold and at the end of the second stage, subjects are tested by a post-test and the questionnaires of goal orientation in English learning are handed out.

According to Ames' theory of goal orientation, the questionnaire is designed to inspect 4 factors: mastery-approach goal, mastery-avoidance goal, performance-approach goal and performance-avoidance goal. Mastery-approach goal orientation means learners focus on the improvement of competence and the fulfilment of tasks; mastery-avoidance goal orientation presents that mastering knowledge is the main goal but students will manage to avoid the errors or mistakes in learning tasks, so they may turn to for help if necessary; in contrast, adopting performance-approach goal orientation stresses on outperforming others in order to get appreciation and compliment by others; learners using performance-avoidance goal are supposed to avoid being worse than others and try to be away failure.

In the questionnaire, the statements are of the 5-scale Likert-type, which the higher score a student gets, the more affirmative attitude he or she towards the statements. To avoid language barrier, the questionnaire is written in Chinese.

\subsection{Instruments}

Three tests and questionnaires are instruments in this study. The questions in tests are carefully chosen from the Question Bank in College of Humanities and Foreign Languages of Xi' an University of Science and Technology. The reliability coefficients of tests are $0.8368,0.8742,0.8295$. These three tests are carried out in a big classroom. After each test, all papers are collected and sealed. Then an instructor corrects these papers according to the standard keys, which can avoid the subjective factors affecting the results of tests. 


\section{Results}

\subsection{Tests Results and Data Analysis}

During the 33-week instruction, three tests are hold respectively and the total scores of each test are 100 . The paired samples T-test is used to analyze the data and the results are shown in Table 2 and Table 3.

Table 2. The statistics of three tests $(\mathrm{N}=125)$

\begin{tabular}{llll}
\hline & Min & Max & $\mathrm{M} \pm \mathrm{SD}$ \\
\hline pre-test & 20.00 & 87.00 & $53.38 \pm 16.89$ \\
mid-test & 23.00 & 86.00 & $54.34 \pm 13.95$ \\
post-test & 14.00 & 87.00 & $57.86 \pm 15.77$ \\
\hline
\end{tabular}

Table 3. Paired sample test

\begin{tabular}{|c|c|c|c|c|c|c|c|}
\hline & \multicolumn{5}{|c|}{ Paired Differences } & \multirow{3}{*}{$\mathrm{t}$} & \multirow{3}{*}{$\begin{array}{l}\text { Sig. } \\
\text { (2-tailed) }\end{array}$} \\
\hline & \multirow{2}{*}{ Mean } & \multirow{2}{*}{$\begin{array}{l}\text { Std. } \\
\text { Deviation }\end{array}$} & \multirow{2}{*}{$\begin{array}{l}\text { Std. Error } \\
\text { Mean }\end{array}$} & \multicolumn{2}{|c|}{$\begin{array}{l}95 \% \text { Confidence Interval } \\
\text { of the Difference }\end{array}$} & & \\
\hline & & & & Lower & Upper & & \\
\hline mid-pre & .96 & 6.09 & .54 & .12 & 2.04 & 1.76 & .08 \\
\hline post-mid & 3.52 & 8.38 & .75 & 2.04 & 5.00 & 4.69 & .00 \\
\hline post-pre & 4.48 & 10.55 & .94 & 2.61 & 6.35 & 4.75 & .00 \\
\hline
\end{tabular}

In Table 2, with the deepening of teaching, the students have forged ahead with their academic performance. In the post-test, the mean has already very approached 60 which mean pass the exam. Generally speaking, these three tests reveal the current situation of college English teaching in China.

Further investigation in T-test (Table 3) shows that although the mean of mid-test is higher than pre-test, yet it doesn't have significant statistical difference $(t=1.76$ and $p=0.08>0.05)$. However, the difference between post-test and mid-test is significant $(\mathrm{t}=4.69$ and $\mathrm{p}=0.00<0.05)$, and similarly, the difference between post-test and pre-test has appeared significant difference as well $(\mathrm{t}=4.75$ and $\mathrm{p}=0.00<0.05)$. These data signify that students are beneficial from autonomous inquiry in English learning and scholastic records have improved steadily; therefore, teaching performance can be enhanced significantly.

In tests, there exists a phenomenon that should be concerned: there is no difference between pre-test and mid-test. This is due to the relative short period of teaching. At that time, learners have not completely adapted the autonomous inquiry model, but with the development of inquiry, the learning motivations are fully activated so the grades in post-test are improved significantly. It obviously indicates that autonomous inquiry learning model needs a long period and in the short run, the effects are not so obvious; however, in the long run, this pattern should effectively enhance learning motivations, successfully achieve the aims and greatly promote the teaching performance.

\subsection{The Construction of Learning Goal Orientation}

At the end of the second stage, questionnaires of Goal Orientation in English Learning have been distributed. All students are asked to finish the questionnaires carefully in the same time. Because five students are absent from the class, 120 valid questionnaires are collected, which shows in Table 4.

Table 4. The descriptive statistics of learning goal orientation $(\mathrm{N}=120)$

\begin{tabular}{lll}
\hline & $\mathrm{M} \pm \mathrm{SD}$ & $\mathrm{N}(\%)$ \\
\hline mastery-approach & $2.15 \pm 1.07$ & $15(12.5)$ \\
mastery-avoidance & $2.59 \pm 0.97$ & $18(15.0)$ \\
performance-approach & $3.19 \pm 1.29$ & $52(43.4)$ \\
performance-avoidance & $2.89 \pm 0.97$ & $25(20.9)$ \\
\hline
\end{tabular}


According the statistical results, $43.4 \%$ of subjects belong to learners of performance-approach goal orientation, and $20.9 \%$ are performance-avoidance goal orientation; however, mastery-approach and mastery-avoidance learners are $12.5 \%$ and $15 \%$. The data reveal that most students pay much attention to grades in their exams. In contrast to mastery goal orientation, they focus on the achievements and certifications rather than the improvement of English proficiency, so the aims of students who have performance goal orientation are to achieve and acquire standards or criteria that society has developed. To put it simply, it is the main motivation to autonomous inquiry learning and it is high related to English test-oriented education in China.

\subsection{Learning Goal Orientation and Teaching Performance}

In order to explore the relationship between learning goal orientations and teaching performance, the changes of scores of different learning goal orientations in pre-test and post-test are analyzed. The details are shown in Table 5.

Table 5. Paired sample test of learning goal orientations

\begin{tabular}{|c|c|c|c|c|c|c|c|}
\hline & \multicolumn{5}{|c|}{ Paired Differences } & \multirow{3}{*}{$\mathrm{t}$} & \multirow{3}{*}{$\begin{array}{l}\text { Sig. } \\
\text { (2-tailed) }\end{array}$} \\
\hline & \multirow[t]{2}{*}{ Mean } & \multirow{2}{*}{$\begin{array}{l}\text { Std. } \\
\text { Deviation }\end{array}$} & \multirow{2}{*}{$\begin{array}{l}\text { Std. Error } \\
\text { Mean }\end{array}$} & \multicolumn{2}{|c|}{$\begin{array}{l}95 \% \text { Confidence Interval } \\
\text { of the Difference }\end{array}$} & & \\
\hline & & & & Lower & Upper & & \\
\hline $\begin{array}{l}\text { mastery-approach } \\
\text { (post-per) }\end{array}$ & 3.27 & 10.35 & 2.67 & 2.47 & 9.00 & 1.22 & .24 \\
\hline $\begin{array}{l}\text { mastery-avoidance } \\
\text { (post-per) }\end{array}$ & 5.11 & 10.82 & 2.55 & .27 & 10.5 & 2.00 & .06 \\
\hline $\begin{array}{l}\text { performance-approach } \\
\text { (post-per) }\end{array}$ & 4.19 & 9.55 & 1.32 & 1.53 & 6.85 & 3.16 & .00 \\
\hline $\begin{array}{l}\text { performance-avoidance } \\
\text { (post-per) }\end{array}$ & 4.96 & 11.76 & 2.35 & .11 & 9.81 & 2.11 & .04 \\
\hline
\end{tabular}

According to the data analysis, it is evident that the changes of scores of mastery-approach \& mastery-avoidance goal orientations are not significant $(\mathrm{P}=0.24 \& 0.06>0.05)$. On the contrary, in post-test and pre-test, the distinction of performance-approach \& performance-avoidance exists statistical significance $(\mathrm{p}<0.05)$.

In autonomous inquiry learning model, the overall grades of learners do increase greatly, which prove that some active and positive factors exist in performance goal orientation and they can successfully activate learning motivations, fulfil inquiry tasks; therefore, in a certain period, they can affect teaching performance significantly. But at the same time, it must see that in performance goal orientations, aims of English learning are utilitarian and students view English learning as an approach to finish social tasks and to get social-granted licences. If the missions are accomplished, motivations for further study will lose accordingly. Therefore, teachers should fully utilize opening and diversity of autonomous inquiry model to put forward to scientific learning tasks and to intervene and supervise learning process from the physiological perspective so that test-oriented aims should be weakened and learners will gradually establish mastery goal orientation to focus on self-improving, understanding and learning foreign language.

\section{Conclusion}

The results indicate that as a learning model, which emphasize on learners' initiative, autonomous inquiry model can improve teaching performance significantly, but it needs a relative long period to motivate them to learning English actively, to stimulate their interest in exploring the foreign language, to cultivate the innovative spirit, to form good habits of autonomous learning and to acquire problem-solving and self-taught abilities that can last a lifetime. On the other hand, according to the data analysis, based on autonomous inquiry pattern, the majority of learners have performance-focused goal orientation; compared with mastery goal orientation, performance goal can improve achievements and promote learning efficiency, but this utilitarian orientation has limitation as well; therefore, reasonably adjusting the learning goal orientation is a vital issue that foreign language learners and teachers should be concerned. 


\section{References}

Ames, C. (1992). Classrooms: Goals, structures and student motivation. Journal of Educational Psychology, 84(3), 261-271. http://dx.doi.org/10.1037/0022-0663.84.3.261

Bartels, J. M., \& Magun-Jackson, S. (2009). Approach-avoidance motivation and metacognitive self-regulation: The role of need for achievement and fear of failure. Learning and Individual Differences, 19, 459-463. http://dx.doi.org/10.1016/j.lindif.2009.03.008

Bjørnebekk, G., \& Diseth, Å. (2010). Approach and avoidance temperaments and achievement goals among

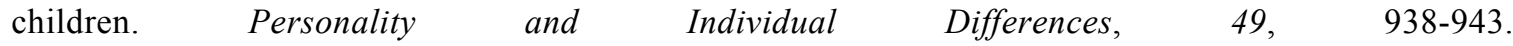
http://dx.doi.org/10.1016/j.paid.2010.07.034

Bruner, J. S. (1967). Studies in Cognitive Growth: A Collaboration at the Center for Cognitive Studies. Wiley.

Gardner, C. (1993). A student's contributions to second-language learning: Affective variables. Language Teaching, 26(1), 1-11. http://dx.doi.org/10.1017/S0261444800000045

Kadivar, P. (2011). Survey on relationship between goal orientation and learning strategies with academic stress in university students. Procedia-Social and Behavioral Sciences, 30, 453-456. http://dx.doi.org/10.1016/j.sbspro.2011.10.089

Kumar, S., \& Jagacinski, C. M. (2011). Confronting task difficulty in ego involvement: Change in performance goals. Journal of Educational Psychology, 103, 664-682. http://dx.doi.org/10.1037/a0023336

Metallidou, P., \& Vlachou, A. (2010). Children's self-regulated learning profile in language and mathematics: The role of task value beliefs. Psychology in the Schools, 47, 776-778. http://dx.doi.org/10.1002/pits.20503

Michou, A. (2013). Personal and contextual antecedents of achievement goals: Their direct and indirect relations to students' learning strategies. Learning and Individual Differences, 23, 197-194. http://dx.doi.org/10.1016/j.lindif.2012.09.005

National research Council. (1996). The National Science Education Standards. Washington D.C: National Academy Press.

Qian, D. (2002). Investigating the relationship between vocabulary knowledge and academic reading performance: An assessment perspective. Language Learning, 52, 513-536. http://dx.doi.org/10.1111/1467-9922.00193

Pintrich, P. R. (1995). Understanding self-regulated learning. San Francisco: CA, Jossey-Bass.

Pintrich, P. R. (2000). Multiple goals, multiple pathways: The role goal orientation in learning and $\begin{array}{llll}\text { achievement. Journal of Educational Psychology, 92(3), 544-555. } & \text {. }\end{array}$ http://dx.doi.org/10.1037//0022-0663.92.3.544

Zhang, J. (2013). The ESP Instruction: A Study Based on the Pattern of Autonomous Inquiry. English Language Teaching, 6(3), 72-77. http://dx.doi.org/10.5539/elt.v6n3p72

\section{Copyrights}

Copyright for this article is retained by the author(s), with first publication rights granted to the journal.

This is an open-access article distributed under the terms and conditions of the Creative Commons Attribution license (http://creativecommons.org/licenses/by/3.0/). 